\title{
Simultaneous Optical/Gamma-ray Observations of GRBs
}

\author{
J. Greiner ${ }^{1}, W$. Wenzel $^{2}, R$. Hudec $^{3}, M$. Varady $^{3}, P$. Stěpán $^{3}$, \\ P. Spurny ${ }^{3}$, J. Florián ${ }^{3}$, E.I. Moskalenko ${ }^{4}$, A.V. Barabanov ${ }^{4}$, R. Ziener ${ }^{5}$, \\ K. Birkle ${ }^{6}$, N. Bade ${ }^{7}$, S.B. Tritton ${ }^{8}$, T. Ichikawa ${ }^{9}$, G.J. Fishman ${ }^{10}$, \\ C. Kouveliotou ${ }^{10}$, C.A. Meegan ${ }^{10}$, W.S. Paciesas ${ }^{10}$, R.B. Wilson ${ }^{10}$ \\ 1 Max-Planck-Institut für Extraterrestrische Physik, 85740 Garching, FRG \\ 2 Sternwarte Sonneberg, 96515 Sonneberg, FRG \\ 3 Astronomical Institute Ondřejov, 25165 Ondřejov, CR \\ 4 Sternberg Astronomical Institute, 119899 Moscow, Russia \\ 5 Thüringer Landessternwarte, 07778 Tautenburg, FRG \\ 6 Calar Alto, German-Spanish Astronomical Centre, 04080 Almeria, Spain \\ 7 Hamburger Sternwarte, Gojenbergsweg 112, 21029 Hamburg, FRG \\ 8 Royal Observatory, Blackford Hill, Edinburgh EH9 3HJ, UK \\ ${ }^{2}$ Kiso Observatory, University of Tokio, Nagano 397-01, Japan \\ ${ }^{10}$ Marshall Space Flight Center, Huntsville, AL 35812, USA
}

\begin{abstract}
This status report presents details on the project to search for serendipitous time-correlated optical photographic observations of $\boldsymbol{\gamma}$-ray bursters. The ongoing photographic observations at nine observatories are used to look for plates which have been exposed simultaneously with a $\gamma$-ray burst detected by BATSE and contain the burst position. The results for the third year of BATSE operation are presented.
\end{abstract}

\section{Strategy and instruments}

We are correlating two independent surveys, namely the photographic plates (optical) of the observatories involved and the BATSE ( $\gamma$-ray) burst data. At present the photographic sky patrols of the observatories Sonneberg, Tautenburg and Hamburg (all Germany), Calar Alto (Spain), Ondřejov (CR), Odessa and Crimea (Ukraine), Dushanbe (Tadshikistan) and Kiso (Japan) are used for the northern hemisphere, and the UK (Siding Spring, Coonabarabran, Australia) and the ESO (La Silla, Chile) Schmidt plates for the southern hemisphere GRBs. This network is still expanding. The instruments which are used for this search are described in Greiner et al. (1994).

\section{Results}

With BATSE detecting and localizing $\approx 1$ GRB per day, and a spatial and temporal optical coverage with the observatories involved of about $80 \%$, we are presently checking 280-300 GRBs per year.

Within the first, almost three years of BATSE observations (1991 April 23 1994 March 31) we have identified simultaneous photographic observations for 
49 GRBs. A first list of plates covering $29 \mathrm{GRBs}$ was given in Greiner et al. 1994. The details for the additional 20 GRBs from the third year of BATSE operation are given in Table 1. For most of these hits, several simultaneously exposed plates from different observational stations are available. Most of these plates are taken in the framework of the Czech meteor patrol (see Hudec 1995 for details) which uses a red sensitive combination of objective and panchromatic emulsion (almost no sensitivity below $400 \mathrm{~nm}$ ). All plates have been investigated by blink comparison. No optical flash or any brightening of an object was found which could be undoubtedly attributed to a GRB. Thus, any optical emission accompanying the high-energy burst must have been less than the minimum detectable optical flux $\left(\mathrm{erg} / \mathrm{cm}^{2} / \mathrm{s}\right)$ of the corresponding plate. Using the peak $\gamma$-ray flux in the $50-300 \mathrm{keV}$ range reached on the $1024 \mathrm{~ms}$ timescale we derive a lower limit of typically $\mathrm{F}_{\gamma} / \mathrm{F}_{\text {opt }}>0.5-40$.

Furthermore, near-simultaneous deep exposures (24 hours before or after GRB) are also registered in the course of the cross-correlation (Table 2). Since these plates have smaller fields of view, the large GRB error boxes are not always covered fully. The last column in Table 2 therefore contains the percentage of the GRB error box area which is covered by the plate. This has been calculated by adding in quadrature a systematic error of $4^{\circ}$ to the statistical error of each burst. In addition to the partial coverage, these plates are mainly taken under programmes which are not related to variability studies; i.e. there is in most cases no plate of the same area (and same filter/emulsion combination) which could be used for blink comparison. Thus, only part of the near-simultaneous plates could be investigated for optical activity. Due to the deeper limiting magnitudes, the blink comparison of plates having suitable comparison plates revealed a number of known as well as new variable stars. However, this optical activity is presumably not related to the GRB phenomenon. We have found no optical flash event. When counting only those plates which contain $100 \%$ of the GRB error box and which have been checked by blink comparison, we can constrain the optical emission within 1-3 hours before or after the GRB to be fainter than 5-7th mag for a $1 \mathrm{sec}$ duration flash or equivalently 12-14th mag for a fading counterpart.

\section{Discussion}

With an increasing number of simultaneous optical observations of GRB locations we can conclude with higher confidence that typical GRBs have (1) optical emission at the time of the burst at a level at least below $\left(\mathrm{F}_{\gamma} / \mathrm{F}_{\text {opt }}\right)^{-1} \approx 2$ and (2) optical emission a few hours after the burst is lower by a factor of 200 than the simultaneous limits.

Acknowledgement: JG and WW are partly supported by the Deutsche Agentur für Raumfahrtangelegenheiten (DARA) GmbH under contract 50 OR 91043 and 50 OR 9201, and by the Deutsches Elektronen-Synchrotron (DESY-PH) under contract $05-5 \mathrm{~S} 0414$. RH is supported by grant 303103 of the Academy of 
Table 1. Simultaneous plates for BATSE GRBs in the third year

\begin{tabular}{|c|c|c|c|c|c|c|}
\hline GRB & $\begin{array}{l}\text { Time } \\
\text { (UT) }\end{array}$ & $\begin{array}{c}\text { Location } \\
\text { (RA, DEC) }\end{array}$ & $\begin{array}{l}\text { No. of } \\
\text { simul- } \\
\text { taneous } \\
\text { plates }^{1)}\end{array}$ & $\begin{array}{c}\text { limiting } \\
\text { magnitude } \\
m_{\mathrm{pg}} \\
\text { (for 1s flash) }\end{array}$ & $\begin{array}{c}\text { Peak flux } \mathrm{F}_{\gamma} \\
\left(\mathrm{ph} / \mathrm{cm}^{2} / \mathrm{s}\right) \\
50-300 \mathrm{keV} \\
1024 \mathrm{~ms} \\
\end{array}$ & $\begin{array}{l}\text { Limit }^{2)} \\
\quad \text { for } \\
\mathrm{F}_{\gamma} / \mathrm{F}_{\text {opt }}\end{array}$ \\
\hline 930424 & $19: 19: 00$ & $67.0^{\circ}, 40.2^{\circ}$ & 0,4 & 3.0 & 1.64 & 0.7 \\
\hline 930514 & $00: 26: 16$ & $170.1^{\circ}+71.0^{\circ}$ & 0,8 & 3.0 & 3) & \\
\hline 930816 & $00: 52: 24$ & $58.5^{\circ}+71.4^{\circ}$ & 0,8 & 3.5 & 3) & \\
\hline 930911 & $23: 16: 01$ & $268.36^{\circ}, 69.07^{\circ}$ & 0,5 & 3.0 & 0.82 & 0.3 \\
\hline 930916 & $20: 19: 23$ & $282.67^{\circ}, 65.28^{\circ}$ & 0,3 & 3.0 & 7.90 & 3.5 \\
\hline 930924 & $01: 02: 55$ & $312.28^{\circ}, 12.67^{\circ}$ & 0,7 & 3.0 & 3) & \\
\hline 931001 & $01: 23: 11$ & $256.95^{\circ}, 46.09^{\circ}$ & $\mathrm{O}, 2$ & 0.5 & 0.47 & 0.02 \\
\hline 931006 & $21: 31: 50$ & $59.89^{\circ}, 65.89^{\circ}$ & 0,6 & 2.5 & 3) & \\
\hline 931101 & $23: 23: 38$ & $133.77^{\circ}, 6.95^{\circ}$ & 0,2 & 2.0 & 0.14 & 0.03 \\
\hline 931126 & $04: 46: 46$ & $156.74^{\circ}, 67.53^{\circ}$ & 0,1 & 0.0 & 0.81 & 0.02 \\
\hline 931126 & $19: 31: 39$ & $1.58^{\circ},-16.62^{\circ}$ & 0,1 & -1.0 & 3) & \\
\hline 931223 & $23: 34: 20$ & $256.31^{\circ}, 41.08^{\circ}$ & 0,2 & 0.0 & 1.84 & 0.05 \\
\hline 940112 & $19: 53: 32$ & $47.85^{\circ}, 64.23^{\circ}$ & 0,4 & 2.5 & 0.26 & 0.07 \\
\hline 940114 & $21: 28: 20$ & $98.19^{\circ},-13.58^{\circ}$ & $\mathrm{O}, 2$ & 1.0 & 3) & \\
\hline 940209 & $20: 00: 01$ & $354.87^{\circ}, 9.02^{\circ}$ & 0,2 & 1.5 & 3) & \\
\hline 940214 & 00:38:08 & $121.63^{\circ}, 57.02^{\circ}$ & 0,3 & 2.5 & 1.91 & 0.5 \\
\hline 940217 & $23: 02: 42$ & $29.02^{\circ}, 5.93^{\circ}$ & $\mathrm{O}, 2$ & 2.0 & 36.21 & 6.4 \\
\hline 940227 & 21:04:14 & $356.63^{\circ}, 43.01^{\circ}$ & 0,3 & 1.0 & 1.05 & 0.07 \\
\hline 940310 & $22: 00: 57$ & $84.86^{\circ}, 49.57^{\circ}$ & 0,6 & 3.5 & 1.58 & 1.1 \\
\hline 940327 & $20: 29: 06$ & $24.12^{\circ}, 52.07^{\circ}$ & 0,5 & 1.0 & 0.43 & 0.03 \\
\hline
\end{tabular}

1) Letters indicate the observatory: $\mathrm{O}=$ Ondrejov

2) For the conversion of the $\gamma$-ray fluxes from $\mathrm{ph} / \mathrm{cm}^{2} / \mathrm{s}$ to $\mathrm{erg} / \mathrm{cm}^{2} / \mathrm{s}$ we have used a power law model of index -1.4 which is the most frequent value (Pendleton et al. 1994). The burst spectra with extreme deviations in slope the error in the conversion can reach up to a factor of 2 . In the case of several simultaneous plates the ratio $\mathrm{F}_{\gamma} / \mathrm{F}_{\text {opt }}$ is calculated for the deepest plate. Note that $\mathrm{F}_{\gamma} / \mathrm{F}_{\text {opt }}$ is a true flux ratio (peak $\gamma$-ray flux in erg/ $/ \mathrm{cm}^{2} / \mathrm{s}$ divided by the optical flux limit in the same units) rather than the usually given "flux" ratio $L_{\gamma} / L_{o p t}$, which is really a fluence ratio, i.e. depends on the burst duration $\left(\mathrm{T}_{90}\right)$ and the exposure time of the plate. $\mathrm{F}_{\gamma} / \mathrm{F}_{\text {opt }}$ is always lower than $\mathrm{L}_{\gamma} / \mathrm{L}_{\text {opt }}$ if the burst duration is larger than 1s.

3) $\mathrm{F}_{\gamma}$ not available due to some missing data types. 
Table 2. Selected near-simultaneous ( \pm 1 day) plates for BATSE GRBs

\begin{tabular}{|c|c|c|c|c|c|c|}
\hline GRB & $\begin{array}{l}\text { Time } \\
\text { (UT) }\end{array}$ & $\begin{array}{l}\text { Location } \\
\text { RA, DEC }\end{array}$ & $\begin{array}{c}\text { Observatory }^{1)} \\
\text { Plate center } \\
\text { (RA, DEC) }\end{array}$ & $\begin{array}{l}\text { Time between } \\
\text { GRB onset and } \\
\text { exposure }^{2)}\end{array}$ & $m_{\mathrm{lim}}$ & $\begin{array}{c}\% \text { of } \\
\text { error } \\
\text { box }\end{array}$ \\
\hline 910505 & $20: 15: 18$ & $178^{\circ} \cdot 6,33^{\circ} .2$ & $\mathrm{~K} 180^{\circ}, 30^{\circ}$ & $-7.5 \mathrm{~h}$ & & $25 \%$ \\
\hline 930511 & 3:47:38 & $270^{\circ} 4,41: 0$ & $\mathrm{Sa} ; 274^{\circ} 96,36^{\circ}: 06$ & $+19.0 \mathrm{~h}$ & $16.0 \mathrm{pg}$ & $30 \%$ \\
\hline 930622 & $3: 28: 15$ & $143^{\circ} 4,14^{\circ}: 0$ & Od; $148^{\circ},+69^{\circ}$ & $+16.0 \mathrm{~h}$ & $14.5 \mathrm{pv}$ & $100 \%$ \\
\hline 930724 & $2: 21: 50$ & $287^{\circ} 6,60^{\circ} 0$ & $\begin{array}{l}\mathrm{Sp} ; 18 \mathrm{~h}+60^{\circ} \\
\mathrm{Sp} ; 18 \mathrm{~h}+60^{\circ}\end{array}$ & $\begin{array}{l}+18.9 \mathrm{~h} \\
+18.9 \mathrm{~h}\end{array}$ & $\begin{array}{l}13.5 \mathrm{pg} \\
12.0 \mathrm{pv}\end{array}$ & $\begin{array}{l}60 \% \\
60 \%\end{array}$ \\
\hline$* 930725$ & $15: 27: 50$ & $264: 9,8.4$ & $\begin{array}{c}\mathrm{Sp} ; 18 \mathrm{~h}+00^{\circ} \\
\mathrm{Sp} ; 18 \mathrm{~h}+00^{\circ} \\
\mathrm{Sa} ; 263^{\circ} 73,12^{\circ} .56\end{array}$ & $\begin{array}{l}+6.8 \mathrm{~h} \\
+6.8 \mathrm{~h} \\
-16.8 \mathrm{~h}\end{array}$ & $\begin{array}{l}12.0 \mathrm{pg} \\
11.0 \mathrm{pv} \\
16.0 \mathrm{pg}\end{array}$ & $\begin{array}{l}90 \% \\
90 \% \\
30 \%\end{array}$ \\
\hline$* 930725$ & $17: 45: 21$ & $88^{\circ} .5,65.7$ & $\begin{array}{l}\mathrm{Sp} ; 6 \mathrm{~h}+80^{\circ} \\
\mathrm{Sp} ; 6 \mathrm{~h}+80^{\circ}\end{array}$ & $\begin{array}{l}+4.5 \mathrm{~h} \\
+4.5 \mathrm{~h}\end{array}$ & $\begin{array}{l}12.5 \mathrm{pg} \\
11.7 \mathrm{pv}\end{array}$ & $\begin{array}{l}50 \% \\
50 \%\end{array}$ \\
\hline 930815 & $5: 26: 42$ & $287^{\circ} 9,-9^{\circ} .3$ & $\begin{array}{l}\mathrm{Sp} ; 19 \mathrm{~h}+00^{\circ} \\
\mathrm{Sp} ; 19 \mathrm{~h}+00^{\circ}\end{array}$ & $\begin{array}{l}+16.6 \mathrm{~h} \\
+16.6 \mathrm{~h}\end{array}$ & $\begin{array}{l}12.0 \mathrm{pg} \\
11.0 \mathrm{pv}\end{array}$ & $\begin{array}{l}60 \% \\
60 \%\end{array}$ \\
\hline *930816 & $00: 52: 24$ & $58.5,71.4$ & $\begin{array}{l}\mathrm{Sp} ; 2 \mathrm{~h}+80^{\circ} \\
\mathrm{Sp} ; 2 \mathrm{~h}+80^{\circ}\end{array}$ & $\begin{array}{l}+0.7 \mathrm{~h} \\
+0.7 \mathrm{~h}\end{array}$ & $\begin{array}{l}12.5 \mathrm{pg} \\
12.0 \mathrm{pv}\end{array}$ & $\begin{array}{l}70 \% \\
70 \%\end{array}$ \\
\hline 931203 & $01: 02: 03$ & $7^{\circ} 63,19: 01$ & $\mathrm{CA} ; 5.5,+17^{\circ}$ & $-4.7 \mathrm{~h}$ & $19.5 \mathrm{pg}$ & $30 \%$ \\
\hline *940310 & $22: 00: 57$ & $84^{\circ} 86,49.57$ & $\begin{array}{l}\mathrm{Sp} ; 6 \mathrm{~h}+40^{\circ} \\
\mathrm{Sp} ; 6 \mathrm{~h}+60^{\circ}\end{array}$ & $\begin{array}{l}-2.3 h \\
-2.3 h\end{array}$ & $\begin{array}{l}12.0 \mathrm{pg} \\
12.5 \mathrm{pg}\end{array}$ & $\begin{array}{l}100 \% \\
100 \%\end{array}$ \\
\hline$* 94070$ & $20: 42: 06$ & $300^{\circ} 2,22^{\circ} .25$ & $\mathrm{Sp} ; 20 \mathrm{~h}+20^{\circ}$ & $+2.3 \mathrm{~h}$ & $12.5 \mathrm{pg}$ & $100 \%$ \\
\hline *940806 & $9: 32: 58$ & $245^{\circ} 2,10^{\circ} 8$ & $\mathrm{Sa} ; 246.54,11^{\circ} 4$ & $+12.2 \mathrm{~h}$ & $15.2 \mathrm{pg}$ & $80 \%$ \\
\hline
\end{tabular}

Notes: Plates marked with an asterisk have been checked by blink comparison.

1) The letters indicate the observatory: $\mathrm{CA}=$ Calar Alto, Od $=$ Odessa, $\mathrm{Sa}=$ Sonneberg astrograph, $\mathrm{Sp}=$ Sonneberg patrol, $\mathrm{K}=$ Kiso Schmidt.

2) The shortest time is given corresponding to the start (end) of exposure for a plate taken after (before) a GRB. Typical exposure times are 30-60 min.

Sciences of the Czech Republic and by grant 202-93-0890 of the Grant Agency of the Czech Republic.

\section{References}

Greiner J., Wenzel W., Hudec R., et al. 1994, in Gamma-ray bursts, AIP 307, p. 408 Hudec R., 1995, this volume p. 376

Pendleton G.N., Paciesas W.S., Briggs M.S., et al. 1994, ApJ 431, 416 